\title{
Desafios do Care: Vulnerabilidades, Políticas e Justiça Social
}

\author{
Justice et Dépendence: \\ Introduction aux Théories du \\ Care.
}

GARRAU, Marie; LE GOFF, Alice.

Paris: Presses Universitaires de France, 2010. $151 \mathrm{p}$.

Pensar sobre o care na sociedade contemporânea é se deixar desafiar e reposicionar os conceitos, tanto nos seus aspectos normativos quanto nos não normativos, e recolocar velhas e novas questões, reconfigurando o cuidado, para construí-lo como política social. Isso implica mudar seu valor para a vida em sociedade e em família, para o mercado e para o Estado, além de desidentificar nesses âmbitos as continuidades com os tradicionais marcadores raciais, sexuais, emocionais e afetivos e constituir o processo necessário ao cuidado democrático e à democratização do cuidado.' Esses desafios se encontram na estruturação das políticas de Estado, na economia nacional e transnacional, ${ }^{2}$ no interior das relações familiares, nos modos como se configuram os cuidados em saúde e em educação, nas políticas de atendimento às crianças e aos idosos, ou como apoiamos as pessoas portadoras de necessidades especiais. Também dizem respeito a como cada um de nós percebe e age frente à necessidade de algum tipo de cuidado do qual todos dependemos pessoalmente ou institucionalmente. Essas relações, que são também de dependência e interdependência, estão reduzidas a díade da divisão sexual e desigual do trabalho, favorecem a privatização, ou os contratos pessoais porque são realizadas em contextos de grande precariedade e, muitas vezes, estão presas às necessida-des de atenção imediata, situação que se confunde frente às fronteiras da autonomia e da vulnerabilidade.

O livro de Marie Garrau e Alice Le Goff, Justice et Dépendence: introduction aux théories du care, publicado em 2010, com 151 páginas, que apresentamos, é absolutamente relevante neste campo reflexivo do cuidado, e nos insere em bases epistemológicas e teóricas nas quais, a reflexão e a prática do care vem se ancorando. O texto nos traz um rol abrangente de interfaces para pensarmos em formas coletivas de ação, nas instituições públicas e familiares, no trabalho e na relação social. A proposta das autoras divide-se em quatro capítulos. No primeiro produzem os fundamentos e as interrogações a respeito de qual modelo poderia ser utilizado para se pensar a dependência em suas múltiplas denominações. Para tal, consideram aspectos que se ligam as representações sobre a precariedade da vida corporal e biológica em fases diversas da experiência humana, como a infância, a velhice ou uma doença, ou frente à fragilidade das identidades. Demonstram como as relações que envolvem a dependência são marcadas por uma ambivalência essencial que se produziu por razões históricas vinculadas a ideia de vulnerabilidade e de incapacidade. Como exemplo, elas recorrem a Linda Gordon e Nancy Fraser $^{3}$ para assinalar como os processos de individualização e a dependência foram inseridos nos programas de proteção social, trazendo uma ascensão de sua psicologização e moralização. Assim Gordon e Fraser, nos apontam o surgimento de um dualismo que foi produzido na posição representacional da dicotomia entre pessoas produtivas e as dependentes e assistidas, de um lado o que é beneficiado por alguma políica de assistência social, para quem são garantidas pensões de aposentadoria e desemprego, e de outro lado, programas de assistência aos mais pobres. Estes últimos, no que tange as proteções sociais, são englobados em uma representação negativa da dependência e são colocados nos pressupostos de incapacidade, da falta de autonomia, da inutilidade social, considerados parasitas, o que os subjetiva como estigmatizados, além de institucionalizarem um forte processo racializado e femilizado.

Neste capítulo as autoras elaboram igualmente, ricas e tensas considerações sobre as noções da vulnerabilidade. As autoras trazem o debate entre as teorias do care e da justiça para considerar a irredutibilidade e a positividade das relações de dependência, tendo em conta os riscos de sujeição abertos para toda relação assimétrica.

Com esta perspectiva entram no segundo capítulo apoiadas em Gilligan ${ }^{4}$ e demonstram 
aspectos positivos da ética do care e da dependência, já que esta última é fundada em uma ontologia social concebida nas noções liberais e, portanto está identificada como lugar de uma experiência moral particular, de aprendizagem e implementação de competências morais específicas e como fundamento das identidades pessoais e morais dos sujeitos. Para elas, Gilligan mostra outra concepção do desenvolvimento moral, diferente da que foi proposta por Kohlberg ${ }^{5}$, em cuja teoria os homens foram associados à racionalidade da justiça e as mulheres apareciam como menos maduras. As autoras apoiam-se positivamente no fato de que Gilligan nos mostra que dependemos um dos outros e que a preservação das relações constitui um jogo moral tão importante quanto o da justiça. Assim, reconhecem em sua obra, uma mudança de paradigma na teoria moral e um novo método de pesquisa na psicologia que permite visibilizar diferentes vozes morais. À dependência dá-se um valor positivo, como lugar de uma aprendizagem moral e de uma experiência moral completa, o que significa que no plano das reivindicações de direitos pode-se partir de outras significações. O reconhecimento de nossas dependências mútuas vai ao encontro do reconhecimento das responsabilidades mútuas, mas esse duplo reconhecimento não significa o sacrifício do sujeito e sim a compreensão do agir com responsabilidade em relação a si mesmo e aos outros. Por isso, as autoras, ainda que ressaltem o valor da teoria do desenvolvimento moral de Gilligan, também se somam às críticas que o feminismo produziu ao binarismo presente na forma de uma ética do cuidado e da justiça. Esta construção de Gilligan acabou por colocar o care ancorado em uma ideia tradicional de solicitude natural das mulheres, pensando em uma equivalência entre a preocupação com os outros e o sacrifício de si, e justificando o confinamento das mulheres no âmbito privado, de uma ética do care feminista que se desenvolve a partir das críticas destes mecanismos que a primeira ideia propaga.

Dessa crítica à visão binária e essencializadora do feminismo, passou-se de uma perspectiva exclusivamente moral para uma perspectiva social e política. Restituiu-se ao care seu duplo contexto histórico e social e ressaltou-se a subordinação das mulheres, aspectos que Garrau e Le Goff, também tornam presentes em seu terceiro capítulo. Nele trabalham com uma linha argumentativa crítica sobre a desvalorização da dependência, e preservam a ideia do care como uma orientação moral importante, que renova um ideal político preciso. Buscam nas reflexões de Joan Tronto 6 aspectos da fundamentação do cuidado nos níveis sociais, políticos e éticos e das consequências da marginalidade da ética do care e de quem proporciona suas tarefas (em sua maioria as mulheres).

Ao lutar contra a marginalidade da ética do care, Tronto torna possível e visível a sua centralidade na vida humana, que é compreendida como relacional e social. Essa definição holística de Tronto torna o conceito de care um conceito crítico e político, que afasta das mulheres e do âmbito privado a responsabilidade pelas práticas que ele envolve e traz para a discussão política as desigualdades fomentadas nestas relações, além de possibilitar o questionamento: quem cuida e em quais condições? Ela não deixa de mencionar os grandes fluxos migratórios globais, que empregam mulheres de determinadas classes e etnias para realizar este trabalho, vinculando-o ainda a outras formas de desigualdades feminilizadas e de mercantilizações da vida íntima?

De acordo com Tronto, uma sociedade que leva a sério as práticas do care toma este debate na vida pública, não a partir de pressupostos que considerem os atores sociais como seres autônomos, iguais e irracionais, mas a partir da ideia de interdependência onde cada sujeito demanda um cuidado específico e oferece diferentes maneiras de atividades do cuidado.

É justamente a este ponto que Garrau e Le Goff dedicam o último capítulo do livro, mostrando que as teorias contemporâneas da justiça não vêm contemplando as realidades familiares vistas frequentemente como harmônicas - em suas desigualdades. Elas insistem que a implementação de princípios da justiça no seio da família, precisa se conectar com as responsabilidades compartilhadas entre seus membros e renovam este quadro de teorias a partir dos argumentos de Eva Kittay ${ }^{8}$ e Martha Nussbaum. ${ }^{9}$

Do trabalho de Kittay extraem a discussão da teoria ralwsiana da justiça, baseada em uma crítica da teoria liberal sobre a dependência, e no modo como Kittay estende as posições feministas do ponto de vista da diferença, da dominação e da diversidade. Kittay apresenta a forma como a interdependência vem se conceitualizando nas teorias do care, pois insiste em unir pessoas consideradas normais como interdependentes e as "anormais" como dependentes. A autora então se concentra em uma noção de dependência extrema e suas questões morais e políticas específicas. Ela reconhece que se fixar somente nas especificidades das formas extremas de dependência produz o risco de reiterar um estig- 
ma já colocado, mas reduzir estas especificidades a interdependência pode criar uma invisibilidade social destas formas de experiência. ${ }^{10}$ Dessa forma, ela propõe uma concepção de justiça que leva a sério a dependência, pois cada membro da sociedade tem fases de dependências em suas vidas e alguns nunca conseguem chegar a uma independência para participar da cooperação social. Segundo Kittay, a consideração central do care e a nossa desigua vulnerabilidade a seu respeito gera o reconhecimento da importância da escolha dos princípios de justiça de um terceiro poder moral, que consiste em mostrar atenção às necessidades específicas do outro. A importância deste poder está na percepção de uma repartição igualitária do care e o reconhecimento, nas circunstâncias da justiça, de estar na lista de bens primários, fundando a ideia que as suas atividades do care precisam ser sustentadas coletivamente como um direito.

Já Naussbaum faz uma crítica a esta ênfase na dependência extrema proposta por Kittay e a sua perspectiva contratualista rawlsniana. A autora reconhece uma dignidade indexada sobre a dependência e a vulnerabilidade do humano, mas ela acredita que toda vida tenha que ser tratada como autônoma, compreende que a liberdade, a possibilidade de definir projetos, constituir objetivos é muito importante para todos os cidadãos, inclusive para aqueles que estão em quadro de dependência extrema.

Assim ela elabora uma teoria da justiça pensando as aproximações das capacidades. A autora desenvolve uma concepção de pessoa em detrimento da importância de certas capacidades para uma vida ser considerada autenticamente humana, e determinar quais capacidades devem ser desenvolvidas politicamente. Naussbaum lista dez capacidades fundamentais: a saúde, a integridade física, a liberdade de pensar, de imaginar, de sentir e de desenvolver sua vida emocional e sua prática, além da noção de pertencimento, interação com outras espécies, a dimensão lúdica da existência e o controle sobre o ambiente. Esta lista pode criar uma norma de avaliação da justiça e um guia de políticas públicas que agencia um envolvimento afetivo e social. É neste ponto que o care se mostra fundamental, pois é possível rever este conjunto de capacidades e suas práticas e atitudes e definilas como centrais da sociedade justa e da ação política, possibilitando o acesso a todos do exercício da cidadania.

Além de expor estes pensamentos que se desenvolvem por meio de ideia de centralidade do care na justiça, Marrie Garrau e Alice Le Goff apontam a essencialidade de distinguir as relações de dependência das relações de dominação, como um aspecto fundamental da existência humana. Elas acreditam então que a instauração de uma cidadania neo-republicana pode constituir uma condição necessária do reconhecimento de uma centralidade existencial e social nas atividades do care.

O livro de Garrau e Le Goff faz uma construção analítica dos aspectos sociais e teóricos que envolvem o care. Esta obra nos apresenta uma análise do care que nos estimula para ver as realidades dos trabalhos demandados no care, as políticas públicas, as construções argumentativas de uma cidadania plena, as desconstruções de estereótipos, os estigmas e a desvinculação necessária dos pressupostos femininos aos quais o care esteve e está conectado. Igualmente, as autoras apontam à necessidade de reflexão social sobre o cuidado, que se desenvolva sob a perspectiva do seu sentido político, econômico, institucional e com o seu consequente desmanche sexista.

\section{Notas}

1 MOLINIER, Pascale; LAUGIER, Sandra; PAPERMAN, Patricia Paperman, 2005.

${ }^{2}$ HIRATA, Helena; KERGOAT, Danièle, et al., 2010.

${ }^{3}$ FRASER, Nancy; GORDON,Linda, 1997.

${ }^{4}$ GILLIGAN, Carol, 1982.

${ }^{5}$ KOLBERG, Lawrence, 1981.

${ }^{6}$ TRONTO, Joan, 1987.

7 HOCHSCHILD, Arlie Russel, 2008.

${ }^{8} \mathrm{KITTAY}$, Eva Feder. 1999.

${ }^{9}$ NOUSSBAUM, Martha. 2011, 2006.

${ }^{10} \mathrm{E}$ para isso ela traz sua experiência. A sua filha Sesha tem uma doença mental severa. A dificuldade de Kittay ao descrever sua filha mostra o significado de critérios de normalidade, pois colocam a sua filha como deficiente. Sobre Sesha, Kittay não gostaria de realizar uma descrição em termos negativos, como aquela que, "perto dos 30 anos não pode comer, se banhar, andar, falar, ler, escrever dizer "mamãe" e "papai"'. Kittay assinala que ela preferiria começar a falar das coisas que sua filha pode fazer, de suas manifestações de afeto e afeição, da maneira que ela aprecia o seu banho ou a música. É importante confrontar os limites cognitivos de Sesha, pois eles moldam o seu estilo de vida e impõem uma estrutura para qualquer tipo de desenvolvimento possível. Ao mesmo tempo, uma concentração muito exclusiva sobre eles traz a exclusão de Sesha e da personalidade moral e da cidadania, tais como o liberalismo definiu em função de critérios intelectuais e de normas de interdependência e produtividade.

\section{Referências}

FALQUES, Jules; HIRATA, Helena; KERGOAT, Danièle, et al. (dir.). Le Sexe de la Mondialisation: Genre, Classe, Race et Nouvelle Division du Travail. Paris: Presses de Sciense Po, 2010. 
FRASER, Nancy; GORDON; Linda. A Geneology of Dependency. In.: FRASER, Nancy. Justice Interruptus: Critical Reflections on the PostSocialism Condition, New York, Routledge,1997. p. 121-149.

GILLIGAN, Carol. Uma Voz Diferente: Psicologia da Diferença entre Homens e Mulheres da Infância à ldade Adulta. Rio de Janeiro: Editora Rosa dos Tempos, 1982.

HOCHSCHILD, Arlie Russel. La Mercantilización de la Vida Íntima: Apuntes de la Casa y el Trabajo. Buenos Aires: Katz Editores, 2008.

HIRATA, Helena Sumiko; GUIMARÃES, NADYA ARAUJO (OrgaS). Cuidado e Cuidadoras: As várias faces do Trabalho do Care, 2013.

KITTAY, Eva Feder. Love's Labor: Essay on Woman Equality and Dependency. New York, Routledge, 1999.

KOLBERG, Lowrence. Essay on Moral Development: The Philosophy of Moral Develepment. San Francisco: Hapert\&Row, 1981.
MOLINIER, Pascale; LAUGIER, Sandra; PAPERMAN, Patricia. Qu'est ce que le "care"?: souci des autres, sensibilité, responsabilité. Paris: Edition PAYOT, 2005.

NOUSSBAUM, Martha. The Fragility of Goodness. Cambridge, Cambridge University Press, 2011.

NOUSSBAUM, Martha. Frontiers of Justice: Disability, Nationality, Species Membership. Cambridge, Harvard University Press, 2006.

TRONTO, Joan. Au-delà d'une Différence de Genre: Vers une Théorie du Care. In.: LAUGIER, Sandra; PAPERMAN, Patricia. (dir). Le Souci des Autres. Editions de l'Ecole des Hautes Etudes en Sciences Sociales, 1987.

Marlene Tamanini Universidade Federal do Paraná

Thays Almeida Monticelli Universidade Federal do Paraná 